Logos. Anales del Seminario de Metafísica

ISSN: 1575-6866

https://dx.doi.org/10.5209/asem.74412

\title{
María Zambrano: el nacimiento de una metafísica
}

Sancho García, Isabel: La joven María Zambrano y su incipiente metafísica femenina. Granada: Editorial Comares, 2020, pp. 138.

Con el único propósito de abordar una investigación acerca del punto de partida de la metafísica zambraniana, el momento en el que echa a andar por su cuenta, esta excelente publicación nos sitúa en una posición privilegiada de claridad para comprender la base sobre la que se levanta todo el pensamiento de María Zambrano. Si bien para ello se abarcan las primeras obras de la autora, a saber, Horizonte del liberalismo, Delirio y Destino y Hacia un saber sobre el alma, se pone especial atención en esta última, que se comenta extensamente por considerarse su primer libro de metafísica.

En su primera parte, en la que se da cuenta del recorrido biográfico de la autora, el lector se siente acompañarla en su camino desde Vélez-Málaga -donde nació-, hasta el exilio, pasando por la ciudad de Segovia y por su formación en las aulas de la Universidad Central de Madrid. Recorriendo sus páginas no se siente la necesidad de preguntarse a qué responde dedicar toda una primera parte de la obra a lo que fue la vida personal de María Zambrano, puesto que su pensamiento parece brotar irremediablemente de su experiencia vital. La atención minuciosa que Isabel Sancho pone en relatar las escenas más relevantes de esta "breve biografía filosófica", repercute muy positivamente en la posterior comprensión de la obra zambraniana y de su deseo de distinción y esfuerzo de autenticidad.

Por ello mismo, un gran acierto del libro es el peso que se le da a figuras como la de Don Blas Zambrano, padre de María, por el que sentía una profunda admiración, Antonio Machado, su primo Miguel Pizarro, la I.L.E (Institución Libre de Enseñanza, donde impartió clases de filosofía), Xavier Zubiri, y por supuesto al que fuera su maestro, Ortega y Gasset: «Todas esas influencias han hecho su camino interior en Zambrano y la han madurado en su visión y penetración del signo de su tiempo». (p. 47). Al fin y al cabo, ¿qué es la filosofía al margen de la vida? Es necesaria una primera parte sobre la vida de Zambrano y la gestación de su pensamiento para luego mostrar cómo en realidad su metafísica guarda una inconfundible raíz vital. Desde su vivencia puede entenderse su significativo rechazo al racionalismo y el positivismo dominantes en la filosofía occidental y su apuesta por una nueva manera de pensar, de vivir, que era la suya propiamente. Un claro ejemplo de ello lo constituye la proyección de la experiencia de la relación paternofilial de Zambrano en su obra: «son estas páginas de María las que resumen la conciencia de la filiación, seguramente más influenciada, cuando las escribe, por una idea a la par mítica y cristiana del Padre que por la freudiana en boga» (p. 10)

Sobre la relación tanto personal como intelectual de María Zambrano con Ortega y Gasset se ofrece una interesante panorámica que arroja una clarividente luz al 
momento del nacimiento de la razón poética. «Quizás, por parte de ella, [la relación] podría describirse como los extremos de un pentagrama: en uno, la determinación -a veces inmadura en su juventud-, a no ser sólo discípula de Ortega, afirmándose como autora propia e independiente; y en otro extremo, un reconocimiento del maestro, como tal, en un sentido no solo intelectual sino en un sentido vital, de orientación de la vida». (p. 31) Lo mismo ocurre en su metafísica: aunque muy pronto toma un camino indudablemente propio no deja de reconocerse siempre en ella, como observa Isabel Sancho, una inconfundible raíz vital de corte orteguiano, así como un horizonte de problemas comunes a los que ambos se enfrentan. El objetivo de esta investigación es precisamente determinar aquello que en la obra de Zambrano es original, aquello que ya no se encuentra en la estela del maestro sino que toma un cauce propio. Hacia un saber sobre el alma, es un libro de una clara herencia orteguiana por lo que toca al punto de partida, sin embargo -y, consideramos, es aquí donde se halla la clave de la tesis que sostiene la autora- «el testigo recibido sólo es responsable de la inspiración zambraniana, y de un sustrato donde comienza su propia reflexión». (p. 35) Desde esta perspectiva se advierten diferencias básicas entre ambos como es la manera de concebir la obra filosófica, así como otras menos inmediatas pero de gran importancia y significación como la apuesta por la mística por parte de María Zambrano.

Presenta Horizonte del liberalismo (1930) como una joven respuesta a una responsabilidad sentida y asumida que la empuja a preguntarse y aclararse sobre lo que necesita España en ese momento, en una situación en que la violencia y la intransigencia estaban permanentemente en la orden del día. La importancia del libro radica, entre otras cosas, en que está presente su concepción de la política y su «relación profunda con la vida», si bien se advierte aún una clara influencia tanto de su padre, Don Blas Zambrano, como de Ortega en la elección de un régimen político muy cercano en su entorno. María busca un nuevo liberalismo en una época que coincide con el final de la dictadura de Primo de Rivera y una inminente Segunda República. Dado que posteriormente la postura política de Zambrano fue modificada y que la autora no tuvo este primer libro muy presente a lo largo de su vida, Isabel Sancho discute la idea de qué fue lo que separó a la pensadora de esta concepción: «... induciría a sospechar si las ideas expresadas en él, en cuanto la elección del liberalismo como régimen más conveniente en ese momento, le pareció demasiado juvenil o demasiado heredada -de Ortega y de su padre-, o demasiado marginal entre las poderosas fuerzas casi telúricas que surgían y se precipitaban en toda Europa». (p. 48).

Delirio y Destino, obra ya de madurez pero que por el contenido atañe al comienzo de su vida, es un libro singularmente autobiográfico porque comprende únicamente la década de los veinte años de Zambrano. Es una década marcada por la Guerra Civil española, la Segunda Guerra Mundial y un penoso exilio: la obra dará cuenta de la propia vida de su autora a la par que de la historia en la que está inmersa. Isabel Sancho señala que no es esta una biografía filosófica o intelectual como tal, aunque de hecho esté marcada por una constante meditación filosófica acerca de su vocación, que Zambrano va descubriendo en esos años de su vida. Este libro, que «es un libro de experiencia», «reúne en sus páginas un trozo de vida política personal y social escrita recordando el pasado, pero con clara conciencia del tiempo en la historia». (p. 61) La cuestión política está centrada, como no podía ser de otra manera, en la circunstancia histórica de España, por la que hace un repaso histórico 
que viene a parar en la caracterización de la sociedad española de su momento como una sociedad «falta de consistencia». Se trata, por tanto, del discernimiento y el encuentro de la propia vocación -y también de la colectiva-, a la que daba siempre una grandísima importancia. La elección de Delirio y Destino como objeto de investigación de esta publicación está justificada, como advierte Isabel Sancho, porque «este libro es decisivo y, quizás, muestre por vez primera una especie de "método histórico zambraniano" o historia, que se construye con, en y desde uno mismo para elevarla al plano general o universal». (p. 63).

Mencionadas estas dos obras, La joven María Zambrano y su incipiente metafisica femenina se centra principalmente en el análisis de Los temas metafísicos de Hacia un saber sobre el alma, como de hecho se titula la tercera parte. Esta obra de Zambrano en la que está ya en marcha su razón poética, como ella misma reconocería más tarde en un pequeño artículo, A modo de autobiografía (1980), supuso una ruptura formal y material con respecto a Ortega y Gasset. De ahí la importancia que tiene su análisis para el propósito de esta publicación. Isabel Sancho abarca el vínculo entre Verdad y Vida, entre Conocimiento y Vida, el tema de la Palabra, el saber de experiencia, la metáfora, etc., y, por supuesto, el Alma. Todos estos temas remiten en último término a la necesaria unión entre razón y pasión: «María postula la unión de pasión y razón, apuntando claramente al concepto que lleva la solución de su futura metafísica, que trabaja y comprende desde la Razón Poética, que no es más que un enraizamiento de la razón en la pasión, o lo que es lo mismo, una razón que trabaja siempre, desde y en el sentir, de la pasión». (p. 83.) La metáfora del corazón, tan presente en la obra posterior de Zambrano, será un ejemplo de recurso que viene a reclamar toda una dimensión abandonada en favor del pensamiento, pues «el corazón no puede desligarse con vida independiente como hace el pensamiento». (p. 94)

Isabel Sancho nos muestra cómo la idea de la Vida está presente en toda la producción zambraniana. Por ello considera preciso atender a ese "fundar la vida" que la pensadora demanda en Delirio y Destino; fundar la vida desde la propia vida, desde la experiencia, desde las entrañas. Quien más, quien menos, ha vivido la experiencia de una crisis personal, vital, y es en estos momentos en los que se deja ver con gran claridad una idea que tiene una significativa estela orteguiana: «que el hombre es una criatura no hecha de una vez. Ni estamos acabados de hacer, ni nos es evidente lo que tenemos que hacer para acabarnos». (p. 100). Por ello mismo, se nos revela una María Zambrano que no cesa en el pensamiento de su tiempo. Esta cuestión, que en Horizonte del liberalismo es evidentemente explícita, no lo es menos en Hacia un saber sobre el alma, donde se hace eco de la crisis que padece Occidente volviendo sobre autores como Husserl o Freud: en las raíces de esta crisis es donde encuentra el pensamiento racionalista de la filosofía occidental.

Junto a todos aquellos elementos que se van prefigurando y presentando ya en Horizonte del liberalismo y en Delirio y Destino, Hacia un saber sobre el alma constituye inequívocamente el principio de la metafísica de María Zambrano, el momento en que su pensamiento suelta la mano del de su maestro y busca sus lugares propios: el Alma, el Corazón, las Entrañas. Así lo muestra con gran claridad esta publicación, que dota al lector de unas coordenadas nítidas para su orientación en las primeras obras de María Zambrano y lo sitúa en una posición inmejorable para continuar el camino por la obra madura. Con todo, Isabel Sancho se esmera en señalar que el pensamiento zambraniano es complejo, a menudo de una muy difícil interpretación, por lo que advenir a una claridad definitiva se torna una tarea 
más bien imposible. Pese a ello, nos atrevemos a señalar que este estudio es un importante paso de aclaración en las cuestiones que aborda e imprescindible para comienzo de cualesquiera investigaciones que vayan a aproximarse a la filosofía de María Zambrano. El lector sabe desde el comienzo lo que va a encontrarse en un estudio que no cae en el error y el sinsentido de perderse en cuestiones nimias que en nada atañen al propósito de la obra.

Sonsoles Ginestal Calvo 